\title{
Pharmacological and Safety Profile of Dexlansoprazole: A New Proton Pump Inhibitor - Implications for Treatment of Gastroesophageal Reflux Disease in the Asia Pacific Region
}

\begin{abstract}
Khean Lee Goh, ${ }^{1 *}$ Myung Gyu Choi, ${ }^{2}$ Ping I Hsu, ${ }^{3}$ Hoon Jai Chun, ${ }^{4}$ Varocha Mahachai, ${ }^{5}$ Udom Kachintorn, ${ }^{6}$ Somchai Leelakusolvong, ${ }^{6}$ Nayoung Kim, ${ }^{7}$ Abdul Aziz Rani, ${ }^{8}$ Benjamin C Y Wong, ${ }^{9}$ Justin Wu, ${ }^{10}$ Cheng Tang Chiu, ${ }^{11}$ Vikram Shetty, ${ }^{12}$ Joseph C Bocobo, ${ }^{13}$ Melchor M Chan, ${ }^{14}$ and Jaw-Town Lin ${ }^{15}$

${ }^{1}$ Department of Medicine, University of Malaya, Kuala Lumpur, Malaysia; ${ }^{2}$ Department of Internal Medicine, Catholic University of Korea, Seoul, Korea; ${ }^{3}$ Department of Internal Medicine, Kaohsiung Veterans General Hospital, Kaohsiung, Taiwan ROC; ${ }^{4}$ Department of Internal Medicine, Korea University College of Medicine, Seoul, Korea; ${ }^{5}$ Division of Gastroenterology, Chulalongkorn University, Bangkok, Thailand; ${ }^{6}$ Division of Gastroenterology, Department of Internal Medicine, Siriraj Hospital, Mahidol University, Bangkok, Thailand; ${ }^{7}$ Department of Internal Medicine, Seoul National University Bundang Hospital, Seongnam, Gyeonggi-do, Korea; ${ }^{8}$ Department of Internal Medicine, University of Indonesia, Depok, Indonesia; ${ }^{9}$ Department of Medicine, The University of Hong Kong, Hong Kong SAR, China; ${ }^{10}$ Department of Medicine and Therapeutics, The Chinese University of Hong Kong, Hong Kong SAR, China; ${ }^{11}$ Department of Gastroenterology and Hepatology, Chang Gung Memorial Hospital Et Chang Gung University, Taoyuan, Taiwan ROC; ${ }^{22}$ Medical Affairs, Takeda Pharmaceuticals (Asia Pacific) Pte Ltd, Singapore; ${ }^{13}$ St. Luke's College of Medicine-William H. Quasha Memorial, Quezon City, Philippines; ${ }^{14}$ Faculty of Medicine and Surgery, University of Santo Tomas Hospital, Manila, Philippines; and ${ }^{15}$ Department of Medicine, Fu Jen Catholic University, New Taipei City, Taiwan ROC
\end{abstract}

Although gastroesophageal reflux disease is not as common in Asia as in western countries, the prevalence has increased substantially during the past decade. Gastroesophageal reflux disease is associated with considerable reductions in subjective well-being and work productivity, as well as increased healthcare use. Proton pump inhibitors (PPIs) are currently the most effective treatment for gastroesophageal reflux disease. However, there are limitations associated with these drugs in terms of partial and non-response. Dexlansoprazole is the first PPI with a dual delayed release formulation designed to provide 2 separate releases of medication to extend the duration of effective plasma drug concentration. Dexlansoprazole has been shown to be effective for healing of erosive esophagitis, and to improve subjective well-being by controlling 24-hour symptoms. Dexlansoprazole has also been shown to achieve good plasma concentration regardless of administration with food, providing flexible dosing. Studies in healthy volunteers showed no clinically important effects on exposure to the active metabolite of clopidogrel or clopidogrel-induced platelet inhibition, with no dose adjustment of clopidogrel necessary when coprescribed. This review discusses the role of the new generation PPI, dexlansoprazole, in the treatment of gastroesophageal reflux disease in Asia.

(J Neurogastroenterol Motil 2016;22:355-366)

Key Words

Asia; Delayed-action preparations; Dexlansoprazole; Gastroesophageal reflux; Proton pump inhibitors

Received: September 19, 2105 Revised: January 27, 2016 Accepted: January 30, 2016

(a) This is an Open Access article distributed under the terms of the Creative Commons Attribution Non-Commercial License (http://creativecommons. org/licenses/by-nc/4.0) which permits unrestricted non-commercial use, distribution, and reproduction in any medium, provided the original work is properly cited.

*Correspondence: Khean Lee Goh, MD

Department of Medicine, Faculty of Medicine, University of Malaya, 50603 Kuala Lumpur, Malaysia Tel: +603-7967-7574, Fax: +603-7967-8841, E-mail: klgoh56@gmail.com 


\section{Introduction}

Gastroesophageal reflux disease (GERD) is a common condition in western countries. Although GERD is less prevalent in Asia than in western countries, its frequency is increasing in the region as disease trends change in line with socio-economic advances and associated lifestyle changes. ${ }^{1,2}$

Data on the extent of the impact of GERD on morbidity and subjective well-being in the Asian population are lacking, and comparisons across the region are limited by differences in the definitions used for GERD, and/or different study methodologies, diagnostic measures, and inclusion criteria. However, epidemiological studies and systematic reviews have increased during the past decade.

Jung $^{3}$ reviewed a series of Asian population-based studies performed before and after 2005, and found that the incidence of GERD has nearly doubled in the past few years. In East Asia, the prevalence of symptom-based GERD increased from 2.5-4.8\% before 2005 to 5.2-8.5\% from 2005 to 2010. In Southeast and West Asia, the prevalence was 6.3-18.3\% after 2005. Similarly, the prevalence of endoscopic reflux esophagitis in East Asia increased from 3.4-5.0\% to 4.3-15.7\%. Thus, GERD appears to be an increasing problem throughout the region.

This increase in prevalence of GERD in Asia may be due to improved diagnosis and better recording, but better consistency in studies from the region is more likely to reflect the true increase. Improved health and growing affluence, along with the accompanying lifestyle changes, are some of the plausible reasons (Table 1). ${ }^{4}$

A Singaporean study found a population prevalence of reflux symptoms of $1.6 \%$, with the prevalence higher among Indians (7.5\%) than among Chinese $(0.8 \%)$ or Malays $(3.0 \%) .^{5}$ A Malaysian study has also reported a higher prevalence among Indians than Chinese and Malays, with a prevalence of at least weekly GERD symptoms of $6.0 \%{ }^{6}$ Interestingly, the prevalence of GERD varies among different ethnic groups, even within Asia. ${ }^{2}$

GERD is associated with substantial reductions in subjective well-being, ${ }^{7}$ lower work productivity, and increased healthcare use. ${ }^{8}$ The GERD in the Asia Pacific Survey (GAPS) found that GERD had a negative impact on well-being for $94 \%$ of respondents in terms of stress ( $68 \%$ of respondents), restrictions to daily activities (50\%), and reduced work productivity (65\%). ${ }^{9}$ Nocturnal symptoms were a particular concern for this group, with $57 \%$ of respondents experiencing night-time symptoms. Nocturnal symptoms have been shown to severely impact subjective well-being and daytime functioning in several studies, ${ }^{10,11}$ and have been noted in up to $90 \%$ of patients with GERD., ${ }^{9,11}$

GERD has been associated with significant loss of work productivity among Korean full-time employees, represented by a loss of 11.7 hours/week versus controls. ${ }^{12}$ Additionally, health-

Table 1. Reasons for Increased Prevalence of Gastroesophageal Reflux Disease in Asia

\section{Effect}

\section{Environmental factors}

Increasing affluence

Decline in Helicobacter pylori infection

Better awareness of GERD by patients and clinicians

Better understanding of GERD terminology

(heartburn, acid regurgitation)

\section{Genetic factors}

Predisposition in certain racial groups

\author{
Older age \\ Adoption of a western lifestyle: \\ Increased dietary fat intake \\ Increased obesity and metabolic syndrome \\ Healthier stomach with increased gastric acid output \\ Improvements in hygiene \\ Increased smoking and alcohol consumption \\ Healthier stomach with increased gastric acid output \\ Increased consultation rate \\ Improved diagnosis \\ Increased consultation rate \\ More accurate diagnosis
}

GERD, gastroesophageal reflux disease. 
related quality of life was significantly impaired in Korean patients with GERD compared with individuals without gastrointestinal symptoms, evidenced by significantly worse scores on all except 2 domains of the Korean version of 36-item short form health survey for GERD patients. ${ }^{13}$

The mainstay of treatment for GERD is proton pump inhibitor (PPI) therapy, which is superior to histamine-2 receptor antagonists and antacids. There are several PPIs available, although many Asian patients with GERD continue to experience symptoms despite treatment with PPIs, suggesting an unmet need in the current treatment of GERD. The GAPS showed that most patients were unsatisfied despite receiving best current therapy. ${ }^{9}$ Importantly, GERD continued to have a negative impact on well-being for $76 \%$ of respondents after treatment, emphasizing the shortcomings of currently available therapy. This review will discuss the role of the most recent addition to the armamentarium, the dual delayed release formulation dexlansoprazole (Dexilant; Takeda Pharmaceuticals USA Inc, Deerfield, IL, USA) and its applicability in the Asia Pacific region.

\section{Proton Pump Inhibitors}

The target for treatment of a wide range of acid-related disorders, including GERD, is reduction of gastric acid secretion. PPIs are widely used to reduce acid secretion in patients with GERD. The factors involved in successful treatment include degree of acid suppression, duration of suppression over the 24-hour period, and duration of treatment. ${ }^{14}$ Suppression of gastric acid secretion by PPIs is at its greatest when proton pumps are the most active. ${ }^{15}$

PPIs are the most effective therapy for patients with GERD. ${ }^{10}$ PPIs are also given in conjunction with non-steroidal anti-inflammatory drugs for patients with risk factors for upper gastrointestinal bleeding, ${ }^{14}$ and for acid suppression in the regimen for Helicobacter pylori eradication. ${ }^{16}$

\section{Clinical Limitations of Proton Pump Inhibitors}

While PPIs are widely regarded as the "gold-standard" of GERD treatment, there are a number of clinical limitations to currently available PPIs. PPIs are associated with limited ability to fully relieve the discomfort of GERD, ${ }^{9,17}$ particularly at night. ${ }^{9,10}$ The GAPS found that only $23 \%$ of respondents felt that their pain was completely controlled with PPIs and $94 \%$ continued to experience breakthrough symptoms; $49 \%$ of respondents used adjunctive medications to control discomfort. In particular, $45 \%$ of respondents found that treatment for nocturnal pain was unsatisfactory. ${ }^{9}$
In the AGA survey, $38 \%$ of patients taking PPIs had breakthrough symptoms, and an overwhelming $65 \%$ of these patients experienced them at night. ${ }^{18}$

The active ingredient in a PPI must be present in high concentrations when the proton pumps are stimulated before and during a meal. ${ }^{15}$ As PPIs are acid labile, they need protection from degradation in the stomach by enteric coating or buffering. ${ }^{19}$ PPIs are rapidly absorbed and subsequently eliminated, leading to a short plasma half-life and ultimately restricting their administration to before meals to achieve their full effect. As pre-meal dosing is inconvenient, this may lead to poor adherence. ${ }^{20}$ However, participants in the GAPS reported good adherence to the prescribed therapies in terms of frequency of administration (87\%), timing of medication (87\%), and mealtimes (88\%). ${ }^{9}$

The effects of PPIs tend to diminish during the 24-hour period enabling resumption of gastric acid secretion by uninhibited, restored, or new proton pumps towards the end of the 24-hour dosing interval (if given once daily). ${ }^{15}$ Due to the lack of complete efficacy of PPIs during the 24-hour period, some patients report taking twice-daily therapy, which may be prescribed by their clinician or may be self-medicated. ${ }^{9}$ In the USA, approximately $30 \%$ of PPI prescriptions are twice daily or on-demand $(22.2 \%$ and $6.8 \%$, respectively). ${ }^{20}$ However, PPIs are not approved as twice-daily therapy for GERD and the safety of this regimen may not have been studied adequately for this indication.

In a recent systematic review of primary care- and communitybased studies, El-Serag et $\mathrm{al}^{21}$ found that $17 \%$ and $28 \%$ of patients had persistent heartburn and regurgitation, respectively, in non-randomized trials; this figure was $32 \%$ and $28 \%$, respectively, in randomized trials. In observational studies, the prevalence of persistent GERD symptoms was $45 \% .^{21}$ In the GAPS, $70 \%$ of participants still experienced breakthrough symptoms despite use of PPIs and $68 \%$ took adjunctive medications. ${ }^{9}$

Interestingly, non-erosive reflux disease (NERD), which is the most common phenotype of GERD, appears to be more refractory to PPI therapy than erosive reflux disease (ERD). ${ }^{22,23}$ A study of 46 patients with ERD, 18 with NERD, and 9 without GERD found a higher PPI response rate among patients with ERD (80\%) than among those with NERD $(67 \%)$. $^{23}$

\section{Interactions with Cytochrome P450 2C19}

Several genetic polymorphisms within the CYP2C19 gene that may have clinical implications have been identified. ${ }^{24}$ The bestdescribed CYP2C19 polymorphic variants are the poor (CYP219*2 and CYP2C19*3) or extensive (CYP2C19*1 and CYP2C19*17) 
metabolism phenotypes, which vary between populations. The frequency of the poor metabolism phenotype ranges from 2-5\% in white and black populations to $13-23 \%$ in Asian populations, while the extensive metabolism phenotype is found in only $4 \%$ of the Chinese population. These genotypes are responsible for interindividual differences in the pharmacokinetics of PPIs, with poor metabolizers having reduced CYP2C19 function. It therefore appears that, for most PPIs, CYP2C19 activity determines the level of drug exposure, pharmacodynamic response, and clinical outcome. ${ }^{25}$

\section{Adverse Interactions with Antiplatelet Therapy}

Although PPIs are generally regarded as safe drugs, with any adverse effects being mostly mild and self-limiting, ${ }^{26}$ recent concerns have been raised about a possible interaction between some PPIs and clopidogrel. Clopidogrel is an antiplatelet agent used for secondary prevention of cardiovascular disease and, because of the risk of gastrointestinal bleeding, a PPI is recommended when both clopidogrel and aspirin are used as dual antiplatelet therapy. ${ }^{27}$ Aspirin may cause gastrointestinal bleeding and the antiplatelet effects of clopidogrel may impair healing of existing gastric erosions and exacerbate gastrointestinal complications. ${ }^{28}$

Table 2. Summary of Characteristics of Proton Pump Inhibitors ${ }^{a}$

\begin{tabular}{|c|c|}
\hline Proton pump inhibitor & Characteristic \\
\hline \multirow[t]{8}{*}{ Dexlansoprazole } & R-enantiomer of lansoprazole \\
\hline & Dual delayed release formulation \\
\hline & Dual-peaked pharmacokinetic profile \\
\hline & 24-hour symptom control \\
\hline & Administration without regard to food \\
\hline & Hepatic metabolism: CYP2C19, CYP3A4 \\
\hline & Weak inhibition of CYP2C19 \\
\hline & No clinically important effect on exposure to the active metabolite of clopidogrel or clopidogrel-induced platelet inhibition \\
\hline \multirow[t]{6}{*}{ Esomeprazole } & S-isomer of omeprazole \\
\hline & Low initial oral bioavailability increasing over time \\
\hline & Hepatic metabolism: CYP2C19, CYP3A4 \\
\hline & Potent inhibition of CYP2C19 \\
\hline & Possible interaction with clopidogrel via CYP2C19 \\
\hline & Delayed absorption with food \\
\hline \multirow[t]{8}{*}{ Lansoprazole } & Constant high bioavailability at therapeutic doses \\
\hline & Rapid onset of maximal acid suppression \\
\hline & Delayed absorption with food \\
\hline & Concurrent antacid therapy reduces bioavailability \\
\hline & Increased theophylline metabolism \\
\hline & Hepatic metabolism: CYP2C19, CYP3A4 \\
\hline & Weak inhibition of CYP2C19 \\
\hline & No clinically important effect on exposure to the active metabolite of clopidogrel or clopidogrel-induced platelet inhibition \\
\hline \multirow[t]{6}{*}{ Omeprazole } & Low initial oral bioavailability $(35-40 \%)$ increasing to $\sim 65 \%$ over time \\
\hline & Dose-dependent kinetics \\
\hline & Delayed absorption with food \\
\hline & Hepatic metabolism: CYP2C19 \\
\hline & Potent inhibition of CYP2C19 \\
\hline & Interaction with clopidogrel via CYP2C19 \\
\hline \multirow[t]{5}{*}{ Pantoprazole } & Constant bioavailability $(\sim 77 \%)$ \\
\hline & Delayed absorption with food \\
\hline & Hepatic metabolism: CYP2C19, CYP3A4 \\
\hline & Weak inhibition of CYP2C19 \\
\hline & No clinically important effect on exposure to the active metabolite of clopidogrel or clopidogrel-induced platelet inhibition \\
\hline
\end{tabular}

${ }^{a}$ Rabeprazole has a non-enzymatic pathway so it is not considered here.

CYP, cytochrome P450. 
Most drugs ( $\sim 90 \%)$ are metabolized by one of 6 of the 50 CYP450 enzymes-CYP1A2, CYP2C9, CYP2C19, CYP2D6, CYP3A4, and CYP3A5, ${ }^{29}$ and $>70 \%$ are metabolized by CY$\mathrm{P} 3 \mathrm{~A} 4$ and $\mathrm{CYP} 2 \mathrm{C} 219{ }^{28}$ Clopidogrel is converted to its active form via CYP2C19 and CYP3A4 in the liver. It is thought that other drugs that are metabolized by the same CYP enzymes as clopidogrel could affect its activation and effects. All PPIs undergo extensive hepatic metabolism, usually by CYP2C19 and CYP3A4, and are thought to compete with clopidogrel for the CYP2C19 binding site, although to varying degrees. ${ }^{30} \mathrm{~A}$ higher clopidogrel-PPI interaction has been observed in patients treated with omeprazole than in those treated with pantoprazole, esomeprazole, or rabeprazole, although the evidence for a clinical effect of clopidogrel-PPI interaction on cardiovascular outcomes is inconsistent and there is no evidence of an effect on mortality. ${ }^{28}$ Importantly, in 2009, the FDA advised against the use of omeprazole and esomeprazole by patients taking clopidogrel $; 31,32$ this recommendation was not applied to the PPI drug class as a whole since not all PPIs have the same inhibitory effect on CYP2C19 (Table 2). The FDA has further clarified this with respect to clopidogrel (Plavix; Bristol-Myers Squibb, New York, NY, USA): "Avoid concomitant use of Plavix with omeprazole or esomeprazole because both significantly reduce the antiplatelet activity of Plavix." ${ }^{33}$ This is supported by the Plavix Full Prescribing Information, which notes that dexlansoprazole, lansoprazole, and pantoprazole have less effect on the antiplatelet activity of Plavix than do omeprazole or esomeprazole. ${ }^{34,35}$

A<smiles>Cc1c(OCC(F)(F)F)ccnc1CS(=O)c1nc2ccccc2[nH]1</smiles>

B<smiles>Cc1c(OC(F)F)ccnc1CS(=O)c1nc2ccccc2[nH]1</smiles>

Figure 1. Chemical structure of (A) dexlansoprazole (R-lansoprazole) and (B) lansoprazole. Dexlansoprazole is one of 2 stereoisomers that are mirror images of each other and are non-superimposable.

\section{Dexlansoprazole}

\section{The Molecule}

Dexlansoprazole is a newly introduced PPI in the Asia Pacific region. Dexlansoprazole is the R-enantiomer of the PPI lansoprazole, a racemic mixture of R-lansoprazole and S-lansoprazole (Fig. 1). ${ }^{19}$ The R-enantiomer is associated with 3-5 times greater maximum concentration $\left(\mathrm{C}_{\max }\right)$, area under the plasma concentration-time curve (AUC), and time to maximum concentration values than the S-enantiomer, and smaller total body clearance values, ${ }^{36}$ so it has greater systemic exposure than lansoprazole and a longer elimination half-life than S-lansoprazole. The active ingredient in dexlansoprazole is (+)-2-[(R)-\{[3-methyl-4-(2,2,2trifluoroethoxy) pyridin-2-yl] methyl $\}$ sulfinyl]-1H-benzimidazole, a compound that inhibits gastric acid secretion. The molecular formula is $\mathrm{C}_{16} \mathrm{H}_{14} \mathrm{~F}_{3} \mathrm{~N}_{3} \mathrm{O}_{2} \mathrm{~S}$, with a molecular weight of 369.36 . $^{37}$

\section{Dual Delayed Release Formulation}

Dexlansoprazole is a novel formulation that employs a dual delayed release technology designed to prolong the concentrationtime profile and provide an extended duration of acid suppression. $^{38,39}$ The dual delayed release technology uses 2 types of entericcoated granules with different $\mathrm{pH}$-dependent dissolution profiles to provide an initial drug release in the proximal small intestine, at a $\mathrm{pH}$ of approximately 5.5 , followed several hours later by another drug release at more distal regions of the small intestine, at a $\mathrm{pH}$ of $\geq 6.75$. Dexlansoprazole therefore produces a dual-peaked

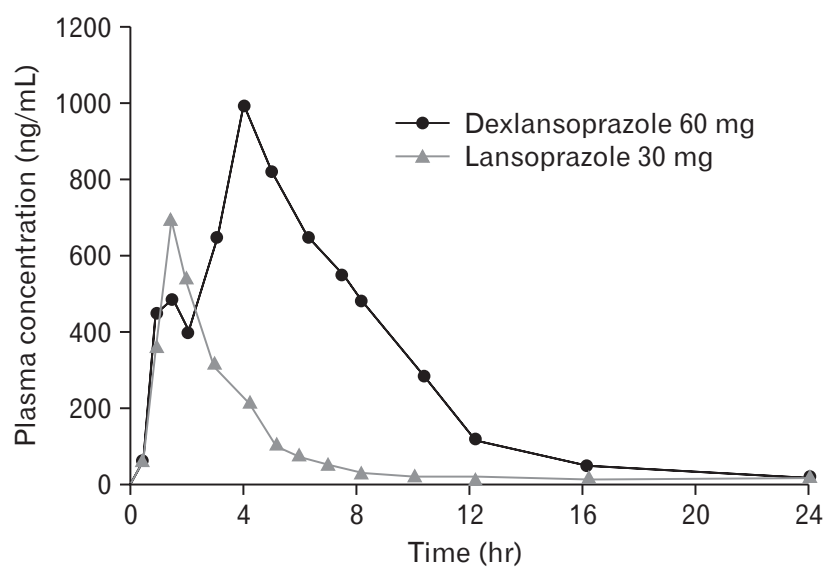

Figure 2. Mean plasma concentration-time profiles for dexlansoprazole and lansoprazole in healthy participants (day 5). Adapted from Vakily et $\mathrm{al}^{39}$ with permission. 
pharmacokinetic profile, as opposed to the single peak seen with conventional PPIs (Fig. 2). ${ }^{39}$ Dexlansoprazole increases the mean intragastric $\mathrm{pH}$ and the duration that intragastric $\mathrm{pH}$ is $>4$ over a 24-hour period. ${ }^{40}$ The optimal dose range is $30-90 \mathrm{mg}$, ${ }^{19}$ and the two doses currently approved for clinical use are $30 \mathrm{mg}$ and $60 \mathrm{mg}$.

Dexlansoprazole is the first PPI with a dual delayed release formulation designed to provide 2 separate releases of medication. In January 2009, the FDA approved dexlansoprazole for the treatment of heartburn associated with symptomatic non-erosive GERD, healing of erosive esophagitis (EE) and maintenance of healed EE at doses of $30 \mathrm{mg}$ and $60 \mathrm{mg}$ once daily.

\section{Pharmacodynamics}

Two prospective randomized studies assessed the 1-day and 5-day pharmacodynamics and pharmacokinetics of dexlansoprazole 30, 60, and $90 \mathrm{mg}$ compared with lansoprazole $15 \mathrm{mg}$ and $30 \mathrm{mg}$ in healthy participants. ${ }^{39}$ Each dose was given 1 hour before breakfast. Assessment after 5 days of therapy (steady state) has shown that, compared with lansoprazole, dexlansoprazole produced significantly greater gastric acid suppression (mean 24-hour intragastric $\mathrm{pH}, 4.55$ versus $4.13 ; P<0.05$ ) and significantly higher 24 -hour mean $\mathrm{pH}$ $(P<0.01)$. Evaluation of the impact of food on dexlansoprazole found a lack of effect of food on the pharmacodynamic parameters and a lack of effect of timing of food intake relative to dosing (Fig. 3). Additionally, no clinically meaningful differences have been found

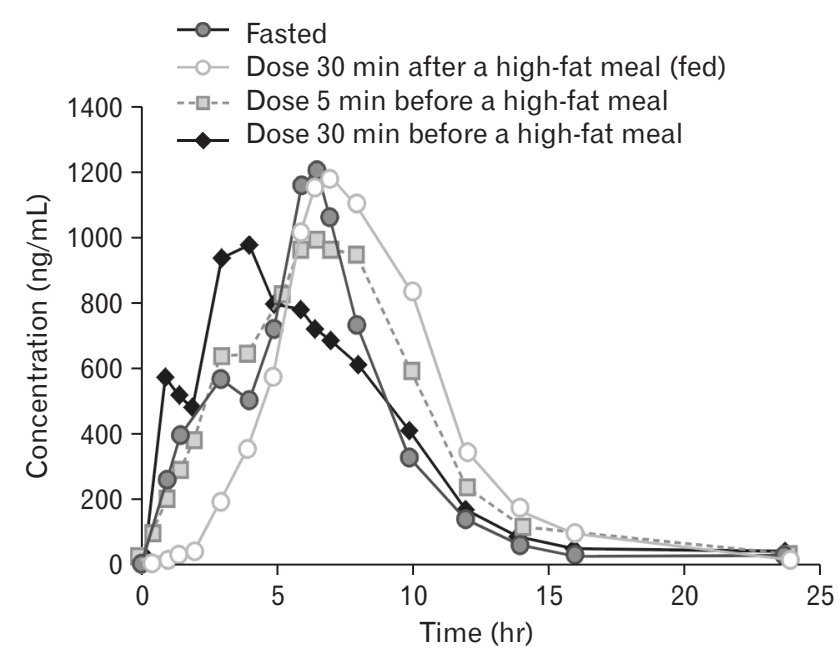

Figure 3. Mean dexlansoprazole plasma concentration-time profile for maximum concentration following administration of a single oral dose of dexlansoprazole $90 \mathrm{mg}$ under fasted and various fed conditions. Reprinted from Lee et $\mathrm{al}^{41}$ with permission from John Wiley \& Sons, Inc. (C) 2009 Takeda Global Research \& Development Center, Inc. when taking dexlansoprazole at different times of the day relative to food (fasted or fed conditions), indicating that it can be taken without regard to food or timing of meals. ${ }^{41,42}$

A comparison of single-dose dexlansoprazole $60 \mathrm{mg}$ with esomeprazole $40 \mathrm{mg}$ found that at $0-24$ hours post-dose, the mean percentage of time with $\mathrm{pH}>4$ was $58 \%$ and $48 \%$, respectively $(P=0.003)$, and the average mean $\mathrm{pH}$ values were 4.3 and 3.7 , respectively $(P<0.001){ }^{40}$ At $>12-24$ hours post-dose, dexlansoprazole resulted in greater mean percentage of time with $\mathrm{pH}>4$ and average mean $\mathrm{pH}$ than esomeprazole (60\% versus $42 \%$ and 4.5 versus 3.5 , respectively; $P<0.001){ }^{40}$

\section{Pharmacokinetics}

The plasma concentration-time profile for dexlansoprazole at steady state is characterized by two distinct peaks and prolonged drug exposure during the 24-hour dosing interval. ${ }^{19,34,39}$ The first peak occurred approximately 1-2 hours after dosing and the second occurred approximately 4-5 hours after dosing (time to maximum concentration was achieved at 5.0-5.4 hours), providing extended drug exposure. Dose proportional increases in $\mathrm{C}_{\max }$ and $\mathrm{AUC}$ values were demonstrated, although no accumulation of drug occurred after multiple once-daily doses. Systemic exposure of dexlansoprazole after 5 days is generally similar to that obtained on day 1 , indicating dose- and time-independent pharmacokinetics of dexlansoprazole. Mean residence time was approximately 3 hours longer for dexlansoprazole (5.6-6.4 hours) than for lansoprazole (2.83.2 hours) demonstrating an extended duration of drug exposure, which is likely to be a result of the dual delayed release technology.

\section{Metabolism}

Dexlansoprazole is metabolized from the active to the inactive state in the liver via CYP2C19 and CYP3A4; approximately 51\% is eliminated in the urine and $48 \%$ in the feces. ${ }^{43}$ No dose adjustments are needed for patients with renal impairment or mild hepatic impairment. However, a lower dose is recommended for patients with moderate hepatic impairment.

Importantly, given that PPIs are thought to protect against gastrointestinal bleeding events in patients taking clopidogrel, ${ }^{26}$ administration of dexlansoprazole does not appear to affect the pharmacokinetics of drugs that are metabolized by CYP2C19. As not all PPIs inhibit CYP 2C19 to the same extent, the potential for a clinically relevant drug-drug interaction with clopidogrel may not be a class effect. ${ }^{43}$

A randomized trial to compare the effects of 4 PPIs (dexlansoprazole $60 \mathrm{mg}$, lansoprazole $30 \mathrm{mg}$, and esomeprazole $40 \mathrm{mg}$, 
with omeprazole $80 \mathrm{mg}$ as a control for assay sensitivity) on the pharmacokinetics and pharmacodynamics of clopidogrel found that generation of the active metabolite of clopidogrel decreased significantly with esomeprazole, but was equivalent with or without co-administration of dexlansoprazole or lansoprazole. ${ }^{43}$ Similarly, inhibition of platelet function was reduced more with esomeprazole than with dexlansoprazole or lansoprazole. The order of effect on clopidogrel potency from most to least effect was omeprazole $>$ esomeprazole $>$ lansoprazole $>$ dexlansoprazole. This study concluded that the potential of PPIs to attenuate clopidogrel efficacy could be minimized by the use of dexlansoprazole or lansoprazole rather than esomeprazole or omeprazole.

\section{Clinical Benefits}

Many patients with GERD take a PPI twice daily to control symptoms, either prescribed by their physician or as self-treatment. ${ }^{9,44}$ However, because of the dual delayed release formulation of dexlansoprazole, once-daily dexlansoprazole could be beneficial as step-down therapy for patients who have symptom control with twice daily PPIs. Fass et $\mathrm{al}^{44}$ found that $88 \%$ of patients taking a PPI twice daily to control heartburn were able to successfully step down to dexlansoprazole $30 \mathrm{mg}$ once daily.

The preferred time of day for dosing of most PPIs is in the morning (in the fasting state). However, this is not always convenient for all patients. Owing to the dual delayed release formulation, dexlansoprazole can be taken flexibly, without regard to food or time of day. A trial to assess the effect of food on dexlansoprazole administered the drug before and after breakfast (under fasted and fed conditions). Increases in dexlansoprazole $\mathrm{C}_{\max }(12-31 \%)$ and AUC (9-21\%) were observed after food, but the differences in intragastric $\mathrm{pH}$ were not clinically relevant. ${ }^{41}$ Dexlansoprazole can therefore be administered regardless of food consumption in most patients, which may increase convenience, and hence compliance. If symptoms do not improve when taking the drug post-food, then pre-food dosing could be considered.

These authors also studied the effect of administering dexlansoprazole at 4 different times of day: before breakfast, lunch, dinner, or evening snack. ${ }^{42}$ There were no clinically meaningful delays to the absorption of dexlansoprazole when dexlansoprazole was administered before lunch, dinner, or an evening snack compared with administration before breakfast, and there were no apparent differences in systemic exposure, with all regimens being pharmacokinetically bioequivalent (Fig. 4). The mean values for the plasma half-life were similar with each regimen (1.27-1.44 hours), as were the mean intragastric $\mathrm{pH}$ profiles for the breakfast, lunch and dinner regimens, when the intragastric $\mathrm{pH}$ quickly increased to $>4$ and was maintained throughout most of the 24-hour post-dose period. It therefore appears that dexlansoprazole provides comparable acid control when administered at different times of the day.

The classical view of food and drug interactions focuses on the
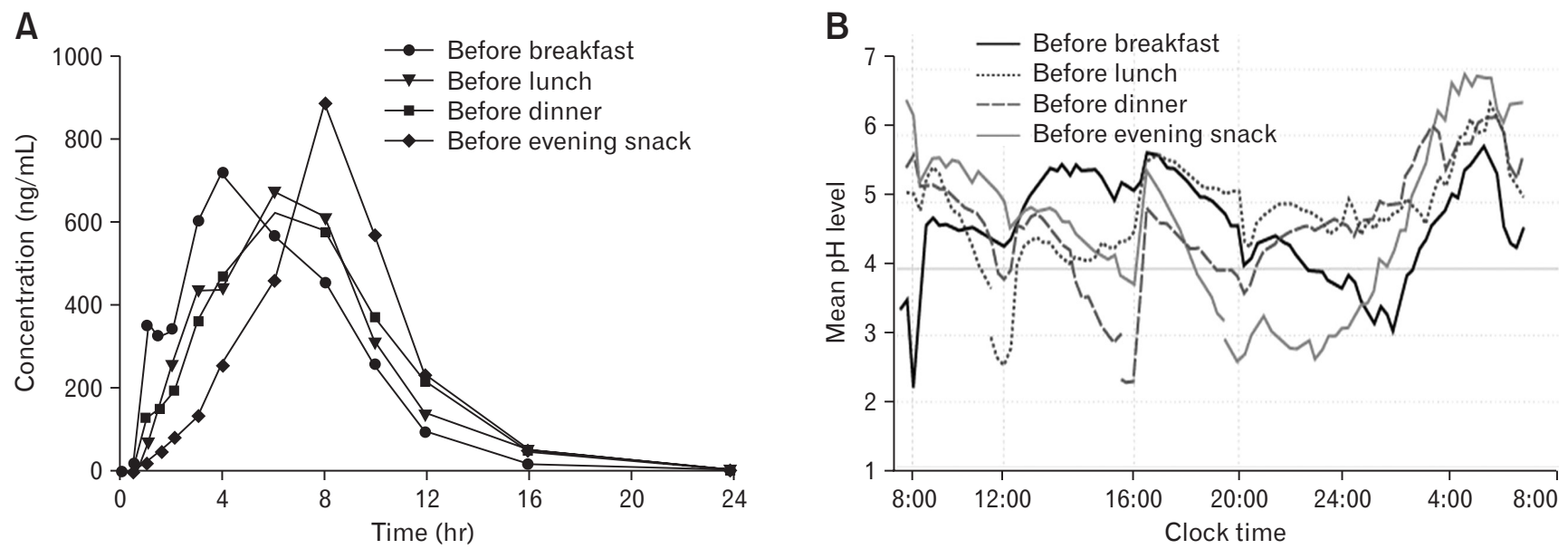

Figure 4. Results on day 5 after daily oral doses of dexlansoprazole $60 \mathrm{mg}$ given 30 minutes before meals or an evening snack. (A) Mean linear plasma concentration-time profiles and (B) mean intragastric $\mathrm{pH}$ measurements. On the 24-hour scale, the x-axis shows hour 8:00 on the morning of day 5 to hour 8:00 on day 6. Upward and downward pointing arrows indicate the beginning and end of the monitoring periods for each regimen, respectively. For the lunch, dinner and snack regimens, data after 8:00 hours on day 6 are transposed to the beginning of the chart so that the mean 24-hour $\mathrm{pH}$ profiles of all 4 regimens can be compared in a single 24-hour view that reflects the diurnal effect of treatment on $\mathrm{pH}$. Reprinted from Lee et $\mathrm{al}^{42}$ with permission from John Wiley \& Sons, Inc. (C2010 Takeda Global Research \& Development Center, Inc. 
alteration of drug absorption, distribution, metabolism, and excretion with food intake. There have been changes in the pharmacokinetics of PPIs with food intake, but studies have shown that these changes are not clinically relevant. In the case of other PPIs the dynamics of time of food and PPI administration is important as acid secretion is dependant largely on food stimulation.

PPIs have no local activity on the gastric mucosa and are absorbed eventually into the systemic circulation from which they are redistributed to the gastric parietal cells. After entry into the parietal cells, PPIs are secreted by active proton pumps and, in the process of this secretion, they irreversibly inhibit the proton pumps. As inactive proton pumps do not secrete the PPI, they escape this inhibition. Subsequent acid secretion comes from activation of these previously inactive proton pumps or from synthesis of new proton pumps. $^{45}$

Thus, a likely inference is that the administration of PPIs must be such that the drug is available in the systemic circulation when the maximum numbers of proton pumps are active, thus permitting maximal activity of the PPI. For this reason clinicians have advocated that the administration of other PPIs 30 minutes before a meal as meals are associated with activation of latent proton pumps.

In the case of dexlansoprazole, the drug maintains a consistent blood level above $125 \mathrm{ng} / \mathrm{mL}$; longer than all the conventional PPIs. Any PPI that can maintain a higher plasma level for longer could theoretically achieve longer acid suppression and this is evident in the dexlansoprazole clinical studies. Therefore, there is no need for clinicians to recommend that dexlansoprazole be taken 30 minutes before a meal. ${ }^{39}$

\section{Clinical Efficacy}

Nocturnal heartburn is known to be associated with daytime sleepiness, decreased subjective well-being, and reduced work productivity and function in performing activities of daily living. A study to evaluate the effect of dexlansoprazole on nocturnal symptoms in 305 patients found that dexlansoprazole was significantly better than placebo in providing relief of nocturnal heartburn and GERD-related sleep disturbances (47.5\% versus $19.6 \%$ and $69.7 \%$ versus $47.9 \%$, respectively; $P<0.001) .{ }^{11}$ Patients experienced significant improvements in nocturnal symptom severity, sleep quality, and work productivity.

In another placebo-controlled study, dexlansoprazole provided significantly more heartburn-free nights $(80.8 \%$ and $76.9 \%$ for dexlansoprazole $30 \mathrm{mg}$ and $60 \mathrm{mg}$, respectively, versus $51.7 \%$ for placebo, $P<0.00001$ ) and reduced symptom severity. ${ }^{38}$ The median percentage of 24-hour heartburn-free days was $54.9 \%$ and $50.0 \%$, respectively, versus $18.5 \%$ for placebo $(P<0.00001)$. Quality of life improvements in patients receiving dexlansoprazole over placebo were confirmed by the patient assessment of upper gastrointestinal disorders quality-of-life index (PAGI-QOL) and the PAGIsymptom severity index (PAGI-SYM).

Metz et $\mathrm{al}^{46}$ found that dexlansoprazole controlled heartburn (91-96\% for 24-hour heartburn-free days and 96-99\% for heartburn-free nights) (Fig. 5) and was superior to placebo for maintaining healed EE over 6 months at doses of $30 \mathrm{mg}$ and $60 \mathrm{mg}$ (life-table analysis: $74.9 \%$ and $82.5 \%$, respectively, versus $27.2 \%$ for placebo; $P<0.00001$; crude rate analysis: $66.4 \%$ for $30 \mathrm{mg}$ and $60 \mathrm{mg}$ versus $14.3 \%$ for placebo; $P<0.00001){ }^{46}$ Importantly, results from the PAGI-QOL and PAGI-SYM questionnaires were consistent with the efficacy results. Results from the PAGI-QOL questionnaire showed that both dexlansoprazole doses achieved significant improvement in the diet and food habits subscale versus placebo, and significantly improved the heartburn/regurgitation subscale and total scores of the PAGI-SYM questionnaire, with no significant differences between the 2 doses. These findings are particularly notable because relief of symptoms for 24 hours is more difficult to achieve than relief of either daytime or night-time symptoms alone.

More recently, Peura et $\mathrm{al}^{47}$ found that dexlansoprazole was more effective in improving both heartburn and regurgitation in patients with NERD compared with placebo $(n=661)$ and in

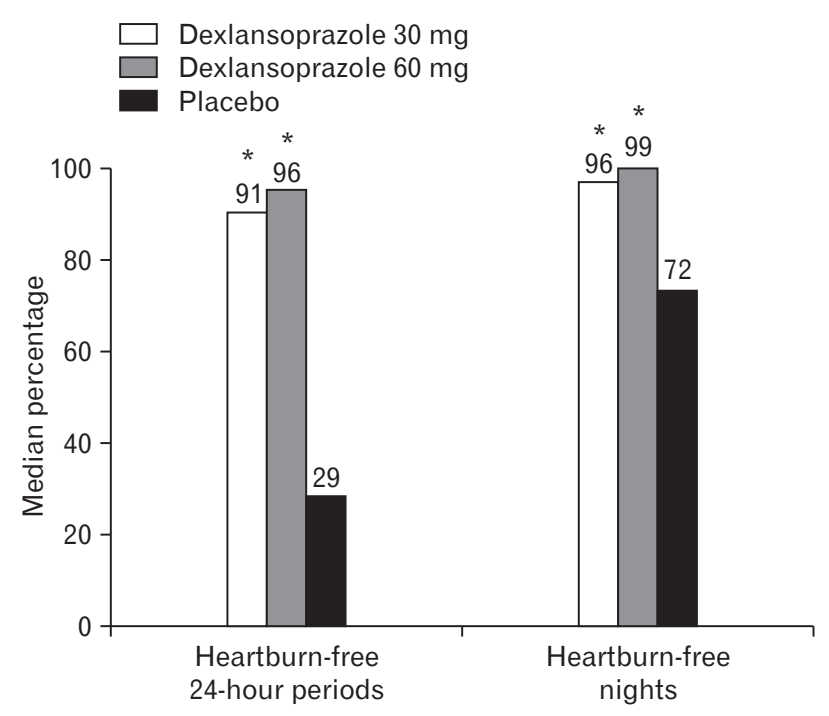

Figure 5. Control of heartburn over 24 hours by dexlansoprazole versus placebo in patients with healed erosive esophagitis (intent to treat population). ${ }^{*} P<0.0025$ vs placebo. Adapted from Metz et $\mathrm{al}^{46} \mathrm{With}$ permission from John Wiley \& Sons, Inc. (C) 2009 Takeda Global Research \& Development Center, Inc. 
patients with EE compared with lansoprazole ( $\mathrm{n}=1909)$. These improvements were maintained for the duration of treatment.

Howden et $\mathrm{al}^{48}$ found that dexlansoprazole $60 \mathrm{mg}$ and $90 \mathrm{mg}$ were superior to placebo for maintaining healed EE (life-table analysis: $86.6 \%$ and $82.1 \%$, respectively, versus $25.7 \%$ for placebo; $P<0.00001$; crude rate analysis: $66.4 \%$ and $64.5 \%$, respectively, versus $14.3 \%$ for placebo; $P<0.00001)$. Both doses were superior to placebo for 24-hour heartburn-free days (95.8\% and $94.4 \%$, respectively, versus $19.2 \% ; P<0.00001)$ and nocturnal heartburn (98.3\% and $97.1 \%$, respectively, versus $50.0 \% ; P<0.00001)$. PAGI-QOL and PAGI-SYM scores for both dexlansoprazole doses were significantly superior to placebo $(P<0.0025)$.

\section{Clinical Safety}

As a class, PPIs are associated with a low incidence of serious adverse events (AEs). ${ }^{49}$ As a higher dose of dexlansoprazole than of conventional PPIs is given to enable the drug to be released twice over a longer period of time, there have been concerns about the higher drug load; however, increased AEs have not been observed after oral administration of dexlansoprazole, even at high doses, because the drug release occurs at 2 distinct time intervals. In addition, as the drug release is $\mathrm{pH}$ dependent, dose dumping has not been observed with dexlansoprazole, and there have been no clinically troubling findings for laboratory values, vital signs, or gastric biopsy results. ${ }^{15}$

The safety profile of dexlansoprazole 30-90 mg has been shown to be similar to that of lansoprazole. ${ }^{50}$ Analysis of pooled data from six phase III randomized controlled trials and a 12-month safety study involved 4270 patients receiving dexlansoprazole 30, 60, or $90 \mathrm{mg}$, lansoprazole $30 \mathrm{mg}$, or placebo. There were no significant differences between dexlansoprazole and placebo or lansoprazole for most of the common treatment-emergent AEs according to the Medical Dictionary for Regulatory Activities preferred term. Although there were more patients with upper respiratory tract infections in the dexlansoprazole $90 \mathrm{mg}$ group in studies of symptomatic GERD, most were associated with a history of seasonal allergies and were not considered related to the study drug.

\section{The Future}

GERD is expected to be a continuing challenge for clinicians in Asia, with potential increase in prevalence. ${ }^{51}$ In the future, the limitations of current treatments will need to be addressed and novel treatments developed. Newer PPIs with improved mechanisms of action, such as dexlansoprazole, are expected to provide improved symptom relief, particularly throughout the 24-hour period. Administration of these newer PPIs with once-daily dosing might lead to better adherence, particularly for individuals with busy lifestyles. Trials of dexlansoprazole are ongoing for treatment of GERD in adolescent patients (EE and NERD). Future research into the use of dexlansoprazole for $H$. pylori treatment, peptic ulcer bleeding, gastrointestinal bleeding (versus intravenous PPIs), and prevention of mucosal injury from non-steroidal anti-inflammatory drugs would lead to better understanding of the extent to which dexlansoprazole could be beneficial. Finally, better understanding of the use of phenotype testing to predict the response to PPIs could lead to improved therapeutic efficacy of this class of drugs.

\section{Implications for Treatment in the Asia Pacific Region}

As disease trends change in the Asia Pacific region, more patients are likely to present with symptoms of GERD. As current PPI regimens do not provide the necessary symptom relief for patients with GERD in Asia, as shown by the GAPS, ${ }^{9}$ there is a need for a more effective longer-lasting medication for GERD patients. Respondents in the GAPS reported that their ideal drug to treat GERD would be one that can free them from pain, especially at night, is safe for long-term use, able to relieve the stress of symptoms, is long acting, and reduced pain quickly.

Treatments with improved response rates that control 24-hour $\mathrm{pH}$ and reduce nocturnal symptoms are needed, and dexlansoprazole has been shown to be effective for the treatment of GERD. Additionally, the once-daily dosing schedule, possible because of its unique mechanism of action that provides two dosing peaks, will ensure better compliance among this group of patients. Dexlansoprazole is well tolerated, with a safety profile similar to lansoprazole, and is not contraindicated in patients who are also taking dual antiplatelet therapy.

Acknowledgements: This manuscript was reviewed by Takeda Pharmaceuticals (Asia Pacific) Pte Ltd for scientific and medical accuracy. Writing support was funded by Takeda and provided by Mary Smith with editorial assistance from Dr Phil Mitchell and Dr Maha Jomaa Sawalhy on behalf of Ward 6 Singapore.

Financial support: This work was initiated and funded in full by Takeda Pharmaceuticals (Asia Pacific) Pte Ltd. 
Conflicts of interest: Authors of this manuscript were recruited by Takeda as Advisory Board Members; all authors fulfilled ICMJE criteria for authorship and approved final version.

Declaration of personal interests: Joseph C Bocobo has served as an advisory board member for Takeda Pharmaceuticals (Asia Pacific) Pte Ltd, Melchor M Chan has served as an advisory board member for Takeda Pharmaceuticals (Asia Pacific) Pte Ltd, Cheng Tang Chiu has served as an advisory board member for Takeda Pharmaceuticals (Asia Pacific) Pte Ltd, Myung Gyu Choi has served as an advisory board member for Takeda Pharmaceuticals (Asia Pacific) Pte Ltd and Yuhan Pharm, Korea, and has received research funding from Dong-A Pharm and Yuhan Pharm, Korea, Hoon Jai Chun has served as an advisory board member for Takeda Pharmaceuticals (Asia Pacific) Pte Ltd, Khean Lee Goh has served as an advisory board member for Takeda Pharmaceuticals (Asia Pacific) Pte Ltd, and as a speaker for AstraZeneca Pharmaceuticals, Abbott Laboratories, Eisai HHC, Ping I Hsu has served as an advisory board member for Takeda Pharmaceuticals (Asia Pacific) Pte Ltd, Udom Kachintorn has served as an advisory board member for Takeda Pharmaceuticals (Asia Pacific) Pte Ltd, Nayoung Kim has served as an advisory board member for Takeda Pharmaceuticals (Asia Pacific) Pte Ltd, Somchai Leelakusolvong has served as an advisory board member for Takeda Pharmaceuticals (Asia Pacific) Pte Ltd, Jaw-Town Lin has served as an advisory board member for Takeda Pharmaceuticals (Asia Pacific) Pte Ltd, Varocha Mahachai has served as an advisory board member for Takeda Pharmaceuticals (Asia Pacific) Pte Ltd, Abdul Aziz Rani has served as an advisory board member for Takeda Pharmaceuticals (Asia Pacific) Pte Ltd, Vikram Shetty was a full time employee of Takeda Pharmaceuticals (Asia Pacific) Pte Ltd at the time of this study, Benjamin C Y Wong has served as an advisory board member for Takeda Pharmaceuticals (Asia Pacific) Pte Ltd, Justin Wu has acted in an advisory and consultancy role for Takeda and AstraZeneca, and as an invited speaker for Abbott Laboratories, Janssen, Lundbeck, and Pfizer.

Author contributions: Myung Gyu Choi, Ping I Hsu, Hoon Jai Chun, Varocha Mahachai, Udom Kachintorn, Somchai Leelakusolvong, Nayoung Kim, Abdul Aziz Rani, Benjamin C Y Wong, Justin Wu, Cheng Tang Chiu, Vikram Shetty, Joseph C Bocobo, Melchor M Chan, and Jaw-Town Lin helped contribute to content and writing of the manuscript; and Khean Lee Goh conceived the idea and is guarantor of the paper.

\section{References}

1. Goh KL. Changing trends in gastrointestinal disease in the Asia-Pacific region. J Dig Dis 2007;8:179-185.

2. Wu JC. Gastroesophageal reflux disease: an Asian perspective. J Gastroenterol Hepatol 2008;23:1785-1793.

3. Jung HK. Epidemiology of gastroesophageal reflux disease in Asia: A systematic review. J Neurogastroenterol Motil 2011;17:14-27.

4. Goh KL. Gastroesophageal reflux disease in Asia: A historical perspective and present challenges. J Gastroenterol Hepatol 2011;26(suppl 1):2-10.

5. Ho KY, Kang JY, Seow A. Prevalence of gastrointestinal symptoms in a multiracial Asian population, with particular reference to reflux-type symptoms. Am J Gastroenterol 1998;93:1816-1822.

6. Rajendra S, Alahuddin S. Racial differences in the prevalence of heartburn. Aliment Pharmacol Ther 2004;19:375-376.

7. Nocon M, Labenz J, Jaspersen D, et al. Health-related quality of life in patients with gastro-oesophageal reflux disease under routine care: 5 -year follow-up results of the ProGERD study. Aliment Pharmacol Ther 2009;29:662-668.

8. Wahlqvist P, Karlsson M, Johnson D, Daelsson J, Bolge SC, Wallander Ma. Relationship between symptom load of gastro-oesophageal reflux disease and health-related quality of life, work productivity, resource utilization and concomitant diseases: survey of a US cohort. Aliment Pharmacol Ther 2008;27:960-970.

9. Goh KL, Choi MG, Hsu WP, et al. Unmet treatment needs of gastroesophageal reflux disease in Asia: gastroesophageal reflux disease in Asia Pacific Survey. J Gastroenterol Hepatol 2014;29:1969-1975.

10. Johnson DA, Katz PO. Nocturnal gastroesophageal reflux disease: issues, implications, and management strategies. Rev Gastroenterol Disord 2008;8:98-108.

11. Fass R, Johnson DA, Orr WC, et al. The effect of dexlansoprazole MR on nocturnal heartburn and GERD-related sleep disturbances in patients with symptomatic GERD. Am J Gastroenterol 2011;106:421-431.

12. Shin WG, Kim HU, Kim SG, et al. Work productivity and activity impairment in gastroesophageal reflux disease in Korean full-time employees: a multicentre study. Dig Liver Dis 2012;44:286-291.

13. Jeong JJ, Choi MG, Cho YS, et al. Chronic gastrointestinal symptoms and quality of life in the Korean population. World J Gastroenterol 2008;14:6388-6394.

14. Hunt RH. Review article: the unmet needs in delayed-release protonpump inhibitor therapy in 2005. Aliment Pharmacol Ther 2005;22(suppl 3):10-19.

15. Metz DC, Vakily M, Dixit T, Mulford D. Review article: dual delayed release formulation of dexlansoprazole $\mathrm{MR}$, a novel approach to overcome the limitations of conventional single release proton pump inhibitor therapy. Aliment Pharmacol Ther 2009;29:928-937.

16. Kongchayanun C, Vilaichone RK, Pornthisarn B, Amornsawadwattana S, Mahachai V. Pilot studies to identify the optimum duration of concomitant Helicobacter pylori eradication therapy in Thailand. Helicobacter 2012;17:282-285.

17. Yamamichi N, Mochizuki S, Asada-Hirayama I, et al. Lifestyle fac- 
tors affecting gastroesophageal reflux disease symptoms: a crosssectional study of healthy 19864 adults using FSSG scores. BMC Med 2012;10:45.

18. American Gastroenterological Association, GERD patient study: patients and their medications, New York, Harris Interactive Inc. 2008.

19. Behm BW, Peura DA. Dexlansoprazole MR for the management of gastroesophageal reflux disease. Expert Rev Gastroenterol Hepatol 2011;5:439-445.

20. Chey WD, Mody RR, Wu EQ, et al. Treatment patterns and symptom control in patients with GERD: US community-based survey. Curr Med Res Opin 2009;25:1869-1878.

21. El-Serag H, Becher A, Jones R. Systematic review: persistent reflux symptoms on proton pump inhibitor therapy in primary care and community studies. Aliment Pharmacol Ther 2010;32:720-737.

22. Long JD, Orlando RC. Nonerosive reflux disease. Minerva Gastroenterol Dietol 2007;53:127-141

23. Cho YK, Choi MG, Lim CH, et al. Diagnostic value of the PPI test for detection of GERD in Korean patients and factors associated with PPI responsiveness. Scand J Gastroenterol 2010;45:533-539.

24. Baldwin RM, Ohlsson S, Pedersen RS, et al. Increased omeprazole metabolism in carriers of the CYP2C19*17 allele; a pharmacokinetic study in healthy volunteers. Br J Clin Pharmacol 2008;65:767-774.

25. Klotz U. Clinical impact of CYP2C19 polymorphism on the action of proton pump inhibitors: a review of a special problem. Int J Clin Pharmacol Ther 2006;44:297-302.

26. Chen J, Yuan YC, Leontiadis GI, Howden CW. Recent safety concerns with proton pump inhibitors. J Clin Gastroenterol 2012;46:93-114.

27. Bhatt DL, Scheiman J, Abraham NS, et al. ACCF/ACG/AHA 2008 expert consensus document on reducing the gastrointestinal risks of antiplatelet therapy and NSAID use: a report of the American College of Cardiology Foundation Task Force on Clinical Expert Consensus Documents. Circulation 2008;118:1894-1909.

28. Tantry US, Kereiakes DJ, Gurbel PA. Clopidogrel and proton pump inhibitors influence of pharmacological interactions on clinical outcomes and mechanistic explanations. J Am Coll Cardiol Intv 2011;4:365-380.

29. Lynch T, Price A. The effect of cytochrome P450 metabolism on drug response, interactions, and adverse effects. Am Fam Physician 2007;76:391-396.

30. Medscape Education. The science of acid control - therapeutic implications: PPI metabolism. Available from URL: http://www.medscape.org/ viewarticle/702505_5 (accessed 1 Apr 2016).

31. US Food and Drug Administration. Information for healthcare professionals: update to the labeling of clopidogrel bisulfate (marketed as Plavix) to alert healthcare professionals about a drug interaction with omeprazole (marketed as Prilosec and Prilosec OTC). Available from URL: http:// www.fda.gov/Drugs/DrugSafety/PostmarketDrugSafetyInformationforPatientsandProviders/DrugSafetyInformationforHeathcareProfessionals/ ucm190787.htm (accessed 29 Apr 2016).

32. US Food and Drug Administration. FDA reminder to avoid concomitant use of Plavix (clopidogrel) and omeprazole. Available from URL: http://www.fda.gov/Drugs/DrugSafety/ucm231161.htm (accessed 29 Apr 2016).
33. US Food and Drug Administration. Plavix (clopidogrel bisulfate) tablet. Available from URL: http:/www.fda.gov/Safety/MedWatch/SafetyInformation/ucm225843.htm (accessed 29 Apr 2016).

34. Wedemeyer RS, Blume H. Pharmacokinetic drug interaction profiles of proton pump inhibitors: an update. Drug Saf 2014;37:201-211.

35. BMS. Plavix. Prescribing Information. 2013. Available from URL: packageinserts.bms.com/pi/pi_plavix.pdf (accessed 1 Jun 2016).

36. Katsuki $\mathrm{H}$, Yagi $\mathrm{H}$, Arimori $\mathrm{K}$, et al. Determination of $\mathrm{R}(+)$ - and $\mathrm{S}(-)$-lansoprazole using chiral stationary-phase liquid chromatography and their enantioselective pharmacokinetics in humans. Pharm Res 1996;13:611615.

37. Takeda. Dexilant (dexlansoprazole). Prescribing Information. Available from URL: www.dexilant.com (accessed 1 Jun 2016).

38. Fass R, Chey WD, Zakko ZF, et al. Clinical trial: the effects of the proton pump inhibitor dexlansoprazole MR on daytime and nighttime heartburn in patients with non-erosive reflux disease. Aliment Pharmacol Ther 2009;29:1261-1272.

39. Vakily M, Zhang W, Wu J, Atkinson SN, Mulford D. Pharmacokinetics and pharmacodynamics of a known active PPI with a novel Dual Delayed Release technology, dexlansoprazole MR: a combined analysis of randomized controlled clinical trials. Curr Med Res Opin 2009;25:627638.

40. Kukulka M, Eisenberg C, Nudurapati S. Comparator pH study to evaluate the single-dose pharmacodynamics of dual delayed-release dexlansoprazole $60 \mathrm{mg}$ and delayed-release esomeprazole $40 \mathrm{mg}$. Clin Exp Gastroenterol 2011;4:213-220.

41. Lee RD, Vakily M, Mulford D, Wu J, Atkinson SN. Clinical trial: the effect and timing of food on the pharmacokinetics and pharmacodynamics of dexlansoprazole MR, a novel Dual Delayed Release formulation of a proton pump inhibitor--evidence for dosing flexibility. Aliment Pharmacol Ther 2009;29:824-833.

42. Lee RD, Mulford D, Wu J, Atkinson SN. The effect of time-of-day dosing on the pharmacokinetics and pharmacodynamics of dexlansoprazole MR: evidence for dosing flexibility with a Dual Delayed Release proton pump inhibitor. Aliment Pharmacol Ther 2010;31:1001-1011.

43. Frelinger AL 3rd, Lee RD, Mulford DJ, et al. A randomized, 2-period, crossover design study to assess the effects of dexlansoprazole, lansoprazole, esomeprazole, and omeprazole on the steady-state pharmacokinetics and pharmacodynamics of clopidogrel in healthy volunteers. J Am Coll Cardiol 2012;59:1304-1311.

44. Fass R, Inadomi J, Han C, et al. Maintenance of heartburn relief after step-down from twice-daily proton pump inhibitor to once-daily dexlansoprazole modified release. Clin Gastroenterol Hepatol 2012;10:247253.

45. Del Valle J, Chey WD, Scheiman JM. Acid peptic disorders. In: Yamada T, Alpers DH, Kaplowitz N, Laine L, Owyang C, Powell DW, eds. Textbook of gastroenterology. 4th ed. Philadelphia: Lippincott Williams and Wilkins 2003:1321-1376.

46. Metz DC, Howden CW, Perez MC, Larsen L, O’Neil J, Atkinson SN. Clinical trial: dexlansoprazole $\mathrm{MR}$, a proton pump inhibitor with dual delayed-release technology, effectively controls symptoms and prevents relapse in patients with healed erosive oesophagitis. Aliment Pharmacol 
Ther 2009;29:742-754.

47. Peura DA, Pilmer B, Hunt B, Mody R, Perez MC. Distinguishing the impact of dexlansoprazole on heartburn vs. regurgitation in patients with gastro-oesophageal reflux disease. Aliment Pharmacol Ther 2013;38:1303-1311.

48. Howden CW, Larsen LM, Perez MC, Palmer R, Atkinson SN. Clinical trial: efficacy and safety of dexlansoprazole MR 60 and $90 \mathrm{mg}$ in healed erosive oesophagitis-maintenance of healing and symptom relief. Aliment Pharmacol Ther 2009;30:895-907.
49. Zhang W, Wu J, Atkinson SN. Effects of dexlansoprazole MR, a novel dual delayed release formulation of a proton pump inhibitor, on plasma gastrin levels in healthy subjects. J Clin Pharmacol 2009;49:444-454.

50. Peura DA, Metz DC, Dabholkar AH, Paris MM, Yu P, Atkinson SN. Safety profile of dexlansoprazole MR, a proton pump inhibitor with a novel dual delayed release formulation: global clinical trial experience. Aliment Pharmacol Ther 2009;30:1010-1021.

51. Cheung TK, Wong BC, Lam SK. Gastro-oesophageal reflux disease in Asia: birth of a 'new' disease? Drugs 2008;68:399-406. 